\title{
LA EDUCACIÓN LAICA EN MÉXICO: ESTUDIOS EN TORNO A SUS ORÍGENES
}

Por Adelina Arredondo (coord.). México: Universidad Autónoma del Estado de Morelos/Bonilla Artigas Editores, 2019, 444 páginas. ISBN: 978-607-8639-01-4 UAEM y ISBN: 978-607-8636-02-3 Bonilla Artigas Editores

El tema de la educación laica, además de ser un objeto de intervención, se ha venido convirtiendo cada vez más en un importante problema de estudio entre investigadores de distintas disciplinas, especialmente entre historiadores, politólogos, antropólogos y estudiosos de las ciencias sociales. Es así como el libro coordinado por Adelina Arredondo, escrito por un grupo interdisciplinario de quince investigadores de diversas universidades e instituciones de educación superior, indagan sobre la emergencia de la educación laica en México.

Cada una de las contribuciones que componen este libro tiene como escenario un momento histórico y un lugar geográfico en los cuales se fueron presentando cambios significativos en la educación mexicana en contextos específicos; además, centran su atención en las condiciones que se fueron creando y en los factores que dieron origen a la educación laica como estrategia y modo de gobernar en diferentes lugares y épocas.

Una característica de este libro colectivo es que nos permite observar la multiplicidad de enfoques, herramientas de análisis y puntos de vista sobre como comprender el proceso de secularización de la sociedad mexicana que derivó en la separación del Estado y la Iglesia, proceso que, poco a poco fue relegando la religión al ámbito privado. Además, el libro centra su atención en las formas de institucionalización, así como en las prácticas que posibilitaron la emergencia de la educación laica en México. Más allá de ofrecer una visión general de un problema específico, en esta obra colectiva se ofrecen claves para comprender la complejidad de un fenómeno que contribuyó a dar forma al actual sistema 
educativo mexicano, pero también para comprender con una visión más amplia, de carácter universal, que da pautas, explicaciones y prácticas para definir, distinguir y comprender las especificidades entre educación secular y educación laica.

Desde su introducción el libro permite comprender su organización y ofrece claves al lector que le permitirán comprender la importancia del problema que se analiza; al mismo tiempo, sirve como guía de lectura que informa, dirige y orienta sobre los aspectos más relevantes que se abordan en cada capítulo. En esta sección también se problematiza el objeto de estudio y la necesidad de reformular, comprender y utilizar de manera rigurosa los conceptos indispensables para explicar la problemática en cuestión.

El libro comienza con la contribución de Anne Staples titulada «Primeros pasos hacia una educación laica en México», y se pregunta ¿puede haber educación laica en una sociedad que estuvo, y en gran medida sigue estando, inmersa en una cultura católica? Y agrega, ¿cómo se define esta cultura, que puede constituir un obstáculo al laicismo, y en qué sentido? Estos cuestionamientos son el punto de partida de un análisis exhaustivo que centra su atención en la forma en cómo se fue desarrollando el proceso de secularización en la sociedad mexicana y su transición a las instituciones educativas de finales del siglo XVIII.

La forma de organizar y gobernar la educación a través de sus dirigentes en instituciones como el Colegio de San Juan Letrán (1816-1863), es el objeto de estudio del segundo capítulo de Rosalina Ríos. En este apartado se analiza el paso que se dio en la administración, de carácter religioso, a una institución secularizada a través de cuatro de sus rectores pues, desde su punto de vista, no se ha explorado a fondo el proceso de secularización de la educación universitaria en estas instituciones. Siguiendo con el análisis de los procesos de secularización en las instituciones educativas, Cristian Rosas Iñiguez trata sobre el establecimiento de Ciencias Eclesiásticas de la Ciudad de México entre 1833 y 1834. La pregunta que se realiza el autor es si esto implicó un avance en la laicización educativa, aunque no deja claro que entiende por secularización y laicidad. El periodo en el que se centra coincide con las reformas liberales impulsadas por Gómez Farías que buscaban la disociación gradual de los elementos religiosos en las instituciones educativas; con 
estas medidas el Estado secularizó la enseñanza y comenzó a tener mayor injerencia en la formación de ciudadanos.

Considerando que los procesos sociales en México no se presentan de forma similar en todo el país, y que cada región adquiere particularidades específicas, en los siguientes capítulos el libro enfoca las condiciones que hicieron posible la emergencia de la educación laica en diferentes regiones de México, tal es el caso de Chihuahua, Oaxaca, Zacatecas, Puebla, Morelos, Chiapas y Aguascalientes. Así, en el cuarto capítulo, la coordinadora del libro, Adelina Arredondo, se encarga de analizar la construcción de la laicidad en una institución ya establecida como secular, el Instituto Literario de Chihuahua entre 1835 y 1868 , periodo en el que se fue ampliando la proporción de profesores laicos y se produjo una tendencia a la laicidad, entendida como ausencia de contenidos, medios, ritos y agentes religiosos. En esta contribución se pone énfasis en las constantes transformaciones que se suscitaron en la sociedad mexicana durante este periodo y sus repercusiones en la educación nacional. De acuerdo con la autora, el cambio fundamental en las instituciones de esta época consistió en que ya no se ocupaban de formar a buenos cristianos, sino a ciudadanos del Estado de derecho.

La influencia de la ideología masónica buscaba el establecimiento de una educación laica sobre bases científicas, como afirma Francisco Martínez Moreno en su colaboración sobre «Los aportes masónicos a la educación laica en México (1833-1917)». Su estudio se divide en cuatro etapas que van de 1833 hasta 1917. El autor destaca que los masones formaron parte de un grupo renovador que estuvo en contra de la enseñanza religiosa y que sus miembros fueron parte importante de un proyecto que culminó con la Constitución de 1917.

Por su parte, Daniela Traffano y Francisco Ruíz analizan el concepto de laicidad en la legislación y los discursos políticos que se suscitaron en Oaxaca (1860-1926). Los autores de este capítulo subrayan que con el impulso de las ideas liberales y la promulgación de las Leyes de Reforma se fortalecieron las instituciones escolares de nivel elemental y los gobiernos oaxaqueños practicaron una política acorde con el precepto de la libertad de enseñanza, y el carácter de la enseñanza laica en los establecimientos escolares oficiales de la entidad fue sancionado 
jurídicamente de manera simultánea con la reforma rebsamiana de la instrucción de finales del siglo XIX.

María Eugenia Chaul Pereyra en su colaboración titulada «La experiencia de la laicidad en las escuelas primarias de la Ciudad de México (1867-1910)», sostiene que desde que se restauró la república, la educación laica fue un instrumento utilizado por el Estado liberal para buscar la unidad nacional y la legitimidad del sistema político. Así, es posible observar la relación entre los cambios en la sociedad y en las instituciones políticas que dieron paso a un proceso de laicidad en las escuelas primarias de la Ciudad de México. A través de los programas oficiales se inició un proceso de homologación de la enseñanza en el que se incluían valores de tipo secular como el reconocimiento a los héroes y el amor a la patria.

Mientras tanto, María del Refugio Magallanes se ocupa de la laicización de la instrucción primaria en Zacatecas y centra su atención en las polémicas en la moral laica entre 1870 y 1912 . Sin dejar de lado las confrontaciones entre la Iglesia y el Estado con relación al problema de la formación moral, señala que la enseñanza de la moral se laicizó en la medida que el discurso político definió su existencia como un compromiso con la humanidad y la civilización, metas que trascendían a las inercias del Estado educador. Las aspiraciones de la moral práctica fueron tres: formar hombres virtuosos, padres fuertes e instruidos y buenos ciudadanos.

Analizar el proceso de toma de conciencia que dio origen a una particular concepción de la educación laica en Puebla durante el régimen porfirista es el objeto de estudio de Jesús Márquez Carrillo. Su aportación se divide en cuatro apartados en los que se estudia el contexto político nacional y local, las ideas sociales regeneracionistas de la élite intelectual hegemónica, la memoria y las prácticas sociales autonómicas de los municipios y la educación laica en el Colegio del Estado, así como la respuesta local a la crisis política en el estallido revolucionario de 1910.

Las manifestaciones de la Iglesia católica en contra de la educación laica se dieron en diversos medios impresos. En el caso del estado de Morelos, Héctor Omar Martínez analiza las publicaciones 
semanales de los semanarios El Grano de Arena y El Despertador publicaciones que dieron origen a una serie de disputas entre los editores y colaboradores de ambos semanarios, entre autoridades civiles y religiosas, por el control de los espacios educativo en Morelos durante el porfiriato.

El capítulo titulado «La importancia de los congresos pedagógicos de finales del siglo XIX» escrito por Amalia Nivón presenta un panorama internacional de los debates en los congresos pedagógicos de finales del siglo XIX. Había una convicción de los representantes en estos congresos pedagógicos de que la educación debía ser única para todo el país, por lo que no se tomaba en cuenta la variedad, cultural lingüística y social de cada una de las regiones del país; lo que se pretendía era uniformar la educación. Para la autora de este capítulo es muy importante revisar cuáles fueron las discusiones sobre los contenidos obligatorios para la enseñanza primaria pública, y destaca que las particularidades del proceso de laicización se hicieron notar en los congresos pedagógicos de instrucción pública como resultado de las tensiones internas que generaba la defensa de la unidad y soberanía nacional a través de la obligatoriedad de la educación pública, el derecho a una educación laica, y el anhelo de una educación basada en principios morales y religiosos conforme a la Iglesia católica.

Por mi parte, como autor de esta reseña, me permito destacar una información que parece no ser suficientemente conocida en el medio de los historiadores de la educación, e incluso ajena a algunos de los participantes de este libro, información que, no obstante, ha sido destacada por Arredondo y González aquí y en otros trabajos previos y que tienen que ver con hechos históricos fundamentales en la construcción de la laicidad educativa, cómo régimen de gobierno de la educación para el caso de México. Me refiero a dos momentos históricos, 1861 y 1874 . En el primer año se promulgó la primera ley educación en México que omitió los contenidos religiosos de la educación pública, aunque limitados en su jurisdicción al Distrito Federal y territorios. En el segundo año que menciono, el Congreso de la Unión elevó a rango constitucional el carácter laico de toda la educación impartida por la federación, los estados y los municipios, prohibiendo además a las órdenes religiosas ofrecer educación. 
Siguiendo la línea de los debates en torno a la educación laica y la educación religiosa, Antonio Padilla Arroyo explora las facetas de los debates que se produjeron entre representantes y voceros del Estado mexicano y la Iglesia católica en Chiapas entre 1882 y 1940. Desde la perspectiva del autor esas polémicas pueden estudiarse desde el marco conceptual del proceso de civilización planteado por Norbert Elias. La conclusión a la que llega el autor de este apartado es que tanto el Estado mexicano como la Iglesia católica se dieron a la tarea de elaborar un pensamiento acerca de la naturaleza, la disposición, los alcances, el destino y el tipo de educación que la sociedad mexicana debía recibir. Esto implicó una serie de debates respecto a su definición.

Yolanda Padilla Andrade revisa las controversias en los discursos antagónicos entre revolucionarios miembros de la Iglesia católica en Aguascalientes entre 1914 y 1917. El marco temporal en el que se fija su estudio no es aleatorio, coincide con el fin del movimiento armado de la Revolución Mexicana y la promulgación de la Constitución de 1917. La autora presenta un escenario muy completo de la situación educativa en Aguascalientes y puntualiza cómo se fue impulsando la educación laica por el director general de Instrucción Pública, en esta región en particular.

Una contribución del libro es que permite ponderar a este problema como algo vigente en las sociedades contemporáneas, ya que las preguntas planteadas en cada uno de los capítulos adquieren nuevos significados cuando se discuten temas como la educación sexual, el derecho de los padres a elegir el tipo de educación para sus hijos, la democracia y los derechos humanos, entre otros. Así el libro cierra con el trabajo de Roberto González Villarreal y Adelina Arredondo titulado «Problematizar la historia de la educación laica. Emergencia, consolidación y declive del régimen liberal de laicidad». En este apartado los autores no pretenden llegar a conclusiones definitivas o establecer conceptos universales, pero desde mi perspectiva, ofrecen claridad para comprender y distinguir los procesos de secularización y laicización. En un primer plano consideran la relevancia y actualidad de la educación laica, para después presentar un breve esquema metodológico de cómo entienden el régimen de laicidad educativa. En un segundo plano realizan un recorrido histórico en los que identifican periodos clave que han modificado el régimen de laicidad educativa, y 
que a través de su análisis permiten apuntar hacía la validez general de sus definiciones.

La consulta de fuentes de información primaria en cada uno de los capítulos enriquece las contribuciones en este libro colectivo. La revisión en diferentes archivos históricos y fondos documentales de cartas, leyes, debates, folletos, diarios y escritos de diferentes épocas fue minuciosa. Lo que también permite a los lectores, especialmente a los que se van iniciando en la investigación, poder consultar cada una de las fuentes referidas. Esto posibilita la apertura de nuevos enfoques, debates y futuras investigaciones.

En la medida en que se va avanzando en el análisis de casos concretos se llega a la conclusión que la emergencia de la educación laica se produjo a través de un intrincado proceso de confrontaciones entre distintos actores en contextos específicos. Por último, el libro es producto de una investigación colectiva, hecha por especialistas, y que también puede ser utilizado como un libro de texto complementario para el estudio de las políticas educativas en la historia de México. Pero, sobre todo, y esto es lo que quiero subrayar con esta reseña, permite comprender para el pasado, para el presente e incluso para proyectos políticos y futuros no solo en México, sino en un mundo cada vez más globalizado, la importancia de investigar y de intervenir políticamente en la construcción de la laicidad educativa, como uno de los instrumentos para garantizar el respeto a la diversidad cultural y religiosa, la formación de ciudadanías más incluyentes y la construcción de las bases de una cultura para la paz.

Finalmente, ¿qué es lo que puede esperar el lector de este libro? En primer lugar, una exposición clara que articula cuáles fueron los procesos históricos que se suscitaron en México desde finales del siglo XVIII y hasta principios del siglo XX. En segundo lugar, permite distinguir los procesos de secularización y laicización que se suscitaron en diversas instituciones educativas, así como los problemas, las rupturas, los conflictos, los avances y los retrocesos en cada caso. En tercer lugar, el lector podrá valorar la importancia histórica y la validez contemporánea de la educación laica. En suma, es un libro que llena un hueco importante que no había sido abordado por los especialistas del área, ya que este no era un problema de la comprensión de cómo se fue 
construyendo nuestro sistema educativo, sino que era un problema político que representó el avance de la educación pública gratuita y universal. Así introduce al lector que no es especialista a reflexionar sobre la importancia de la educación laica a través de diversas miradas, perspectivas teóricas y metodológicas.

Alejandro Ortiz Cirilo Profesor investigador de tiempo completo titular «A» Centro de Estudios sobre la Educación «Celia Muñoz Escobar» de El Colegio de Morelos alejandro.ortiz@elcolegiodemorelos.edu.mx 